Revista Iberoamericana. Vol. LXIV, Núms. 182-183, Enero-Junio 1998; 171-192

\title{
E A MÁGICA? A REPRESENTAÇÃO DA REALIDADE SOCIAL EM JORGE AMADO E GABRIEL GARCÍA MÁRQUEZ
}

\author{
POR
}

\author{
Renata R. Mautner Wasserman \\ Wayne State University
}

Desde o princípio, a literatura americana (de norte a sul) impôs a si mesma a tarefa de representar a realidade do Novo Mundo, quaisquer fossem, em cada época, as definições de "realidade" " "representação". Portanto essa literatura se dirige, também desde o princípio, a dois públicos, o conterrâneo ao qual assegura ao mesmo tempo o interesse de condições locais consideradas especiais e a própria validez como literatura, e outro, externo, cuja atenção também tem função validante. Para simplificar, podese dizer que solicita essa atenção externa através da produção de conteúdos que combinam o familiar para consumo interno e o exotismo para consumo externo, e de formas que adotam - ou ecoam - modelos estabelecidos externamente e que abrem a possibilidade do que se poderia denominar uma canonicidade transnacional, ou transcultural.

Flora Süssekind examina a maneira pela qual, nos primeiros romances brasileiros, um realismo para consumo interno depende de relatos de viajantes sobre um Brasil exótico. Por outro lado, o artigo de Fredric Jameson, "Third World Literature in the Era of Multinational Capitalism", exemplifica o que acontece quando falha a parte do projeto artístico dirigido ao leitor externo; o custo é bastante alto, quando um intelectual americano reconhecidamente interessado tanto pela arte como pela política de países do Terceiro Mundo se baseia em duas obras literárias para caracterizar toda a produção desses países como sendo atrasada e alegórica, e assim reiterar a distância cultural que separa os centros de cultura das suas margens. Jameson confessa a sua inveja de um "leitor Outro, para o qual a narrativa, que nos parece convencional ... tem uma originalidade de informação cultural e um interesse social de que não somos capazes de compartilhar" e sua nostalgia pela possibilidade de uma obra em que ainda não se tenha dado a separação entre os conteúdos político e psicológico característica do realismo ocidental $(66,69)$. Jameson aborda ainda, sem a discutir, a necessidade de uma forma literária prestigiosa para a aceitação de um conteúdo exótico. Replicando a Jameson, Aijaz Ahmad, em "Jameson's Rhetoric of Otherness and the 'National Allegory", levanta a questão do alcance do modernismo: enquanto Jameson reitera o velho conceito europeu segundo o qual o Novo Mundo se constitui em instância 
redentora de um Velho Mundo decadente e alienado, Ahmad rejeita essa divisão de trabalho entre três partes do mundo assim como as atribuições de valores implícitas em análises literárias que nela se baseiam. ${ }^{1}$

Definem-se assim três zonas problemáticas: a da representação, em que entra a questão do exotismo; a da distribuição ou recepção, complicada por dois "horizontes de espera", para usar do termo de Jauss; e a dos sistemas literários nos quais se originam e se inserem as obras sob consideração.

Em certo momento (que pode variar segundo o crítico), aparece na América Latina um conjunto de obras literárias classificadas como de "realismo mágico", expressão agradavelmente paradoxal que por um lado denota um interesse talvez até antiquado pela relação entre literatura e "realidade", ligado a noções tradicionais sobre representação, e que por outro lado aceita elementos de "irrealidade" ou "supra-realidade" os quais, num paradoxo suplementar, passam a constituir o fundamento de uma "suprarepresentatividade". Especificamente, a expressão se refere a um conjunto de obras cujo protótipo é Cem anos de solidão de Gabriel García Márquez, e que se caracteriza por uma linguagem que conscientemente confere literariedade ao falar quotidiano local e inclui incidentes que não podem ser explicados - ou que o romance se recusa a explicar-em termos de leis físicas ou de noções correntemente aceitas de causalidade ou de desenvolvimento histórico e psicológico.

Além disso, as obras sob tal rubrica surgem, em geral, numa cultura periférica periférica, diga-se logo, em relação às que se consideram centrais e tem o poder material de impor tal definição-, mas, ao mesmo tempo, conseguem reconhecimento crítico e boas vendas nessas culturas centrais. São, ademais, escritas em prosa, depois dos anos vinte deste século, ou seja, após o triunfo do movimento literário que se conhece como modernismo nos Estados Unidos, Europa e Brasil, ou Vanguardismo na América espanhola. ${ }^{2}$ A observação é válida não só no âmbito inter- como também no intranacional. Emir Rodríguez Monegal aponta cuidadosamente não só as raízes autóctones do aparecimento e sucesso desses romances, como também as condições culturais, econômicas e políticas das quais dependem: o crescimento urbano pós-guerra que criou um público leitor servido por novas casas editoriais; a política cultural externa tanto da Espanha franquista quanto de Cuba pós-castrista, ambas interessadas em estimular um mercado interamericano do livro (18-23); o interesse dos Estados Unidos em garantir a cooperação da América Latina durante a segunda guerra mundial e a guerra fria (3233). Tudo isso e mais afetam o fenômeno do "boom", associado com os romances de "realismo mágico" ou, segundo o termo de Alejo Carpentier, do "real maravilhoso".

\footnotetext{
' Para uma discussão mais pormenorizada do papel do exotismo na formação de "literaturas de nacionalidade" consultar Wassermann.

${ }^{2}$ Não tocarei aqui no assunto vasto e complexo da poesia do modernismo, exceto para notar que ela desempenhou um papel extremamente importante na literarização de assuntos e de formas de linguagem até então banidos da literatura.
} 
As inovações formais e temáticas introduzidas pelo modernismo permitem ao leitor aceitar o aspecto "mágico" desse realismo como simples —ou complexaexpressão metafórica de condições excessivamente reais, mas estranhas à experiência quotidiana de centros de cultura mais poderosos, ou seja, como a representação realista de condições que, embora sejam da maior importância para as culturas em que se produzem, não o são para as culturas centrais, caindo fora dos parâmetros que, para estas, delimitam o "real". ${ }^{3}$ Assim, segundo Neil Larsen, por exemplo, o realismo "mágico" designa "uma forma de narrativa literária que, porquanto se assemelhe ao modernismo em sua preferência por experimentos formais, difere dele também em virtude de sua pretensa relação mimética para com uma realidade latino-americana que se diz extravasar formas realistas tradicionais de representação". ${ }^{4}$ Desta maneira, a classificação de uma obra como de "realismo mágico" baseia-se numa definição da natureza de certos textos, da forma pela qual se enquadram em certo conceito de representação, e da sua posição em relação a outros textos —ou das culturas em que se originam em relação a outras culturas - assim como de um questionamento implícito e necessário do conceito de realidade. $\mathrm{O}$ fato de tornar possível tal questionamento, $\mathrm{e}$ de mostrar que ele se origina em definições culturalmente elaboradas, e não dadas pela natureza das coisas, é parte do caráter desestabilizador de tais ficções.

Por outro lado, o realismo mágico caracteriza-se também por uma qualidade sedutora, que torna atraente essa mesma desestabilização. Os textos que a exibem diferem de textos classificados como modernistas, precisamente, em parte, por serem menos agressivos e oposicionais, embora usem de muitos dos "macetes" (como talvez os chamassem os formalistas russos em humor informal) do modernismo. Especifica-

\footnotetext{
${ }^{3}$ A expressão "realismo mágico" foi usada em 1925 por Franz Roh para descrever o pósexpressionismo alemão em pintura. Referia-se a "uma visão mágica de uma realidade artisticamente produzida e iluminada de forma não-enfática" (veja-se Seymour Menton, Magic Realism 19; citado em Maylan C. Mills 114). Atribui-se a Alejo Carpentier a extensão do conceito à literatura latino-americana, em 1949, no prefácio original de El reino de este mundo (embora Carpentier tenha usado a expressão real maravilloso). A primeira aplicação crítica rigorosa da expressão é geralmente atribuida a Angel Flores, em "Magical Realism in Spanish American Fiction." Flores vê os primeiros sinais de um "realismo mágico" hispano-americano nas obras de Borges e Mallea, as quais redescobrem traços estilísticos encontrados em Proust e Kafka, Gogol, Dostoyevski, E.T.A. Hoffmann, von Arnim, Kleist, Poe e Melville, entre outros (188) e fogem às classificações costumeiras de românticas, realistas ou naturalistas, embora continuem a apresentar características dessas escolas. Flores também atribui certos traços dessas obras a uma tradição local de integração do real com o fantasioso, que principia nas próprias cartas de Colombo e na Relación de Cabeza de Vaca (189). Da maior importância, no entanto, para a compreensão do valor atribuído a essas obras em seus lugares de origem, é a conclusão de que, embora grande parte da literatura hispano americana precedente tenha sido de qualidade inferior (188), essas novas obras "marquem talvez a origem de uma ficção genuinamente latino-americana", uma "expressão autêntica" da América Latina (192).

${ }^{4}$ Reading North by South (67).
} 
mente, esses textos, enquanto que "mágicos", aceitam as liberdades que o modernismo toma com respeito a noções de causalidade, temporalidade, estabilidade psicológica, e também as suas "brincadeiras" sintáticas e semânticas; rejeitam, ao mesmo tempo, a relação tensa que o modernismo estabelecera com a política em sentido mais direto e explícito. Como a questão da posição política tanto do realismo mágico quanto do modernismo é discutida freqüente e acaloradamente, diga-se por enquanto, só que, embora seja possível configurar-se uma oposição entre modernismo e um realismo politicamente comprometido, é igualmente possível afirmar que a subversão modernista abre a linguagem literária a discursos e experiências -inclusive políticosinteriormente marginalizados. ${ }^{5}$

Partindo de posições bem diferentes, tanto Rodríguez Monegal (40, 55) quanto Neil Larsen demonstram a relação entre textos "comprometidos" e o modernismo; para Larsen é essa uma relação fundamental à política literária latino-americana dos anos sessenta em seus contatos com o mundo literário além de suas fronteiras: "Proponho" diz ele, teleologicamente, "que, na medida em que se sentiu obrigada a transpor o abismo imperial e integrar o Norte com o Sul, a política da Nova Esquerda, de solidariedade para com movimentos de libertação nacional e lutas cultural-nacionalistas, teve que se apropriar de um discurso modernista de utopianismo estético". Com isso, ainda segundo Larsen, estabeleceu-se uma definição do modernismo como modalidade estética universal, a qual não foi rejeitada pelos escritores do "boom" (17).

Quanto à história do "realismo mágico": em geral atribui-se a Alejo Carpentier a aplicação do termo à literatura latino-americana, quando trouxe para a escrita erudita uma parte importante e negligenciada da cultura cubana - a herança africana- e a entrelaçou com as relações pessoais e culturais que o ligavam à Europa. Ampliaramse assim os limites tradicionais do realismo ou seja, do que o realismo abrange como realidade "literarizável". O próprio Carpentier produziu mais tarde romances que tem mais em comum com o antigo gênero da alegoria (por exemplo, Os passos perdidos) do que com um realismo "mágico"; a passagem possível de um ao outro constitui mais um exemplo da continuidade entre formas novas e antigas. Ao mesmo tempo, a definição ampla de realismo "mágico" também inclui a obra de Jorge Luis Borges em sua veia mais abstrata, a qual produziu não tanto alegorias como quebra-cabeças intelectuais cujo referente não são as contingências políticas do próprio modo de produção, mas as contingências morais e intelectuais do que se consideraria genericamente humano. As abstrações dos contos mais famosos de Borges têm sido consideradas mais uma fuga à política do que uma exploração de idéias; tal "fuga" tem sido considerada, por sua vez, como uma tomada de posição política em relação aos acontecimentos históricos das últimas décadas. No entanto, essas perspectivas críticas

\footnotetext{
${ }^{5}$ Em "Poetics of the Americas" Charles Bernstein, ao examinar a obra de poetas negros do Caribe, discute as possibilidades de subversão que lhes foram oferecidas pelas conquistas do modernismo no âmbito da linguagem.
} 
nos dizem muito sobre a história da crítica dos últimos anos, menos sobre a natureza e o alcance da obra de Borges.

A importância dada a esses julgamentos sobre o grau de realismo de uma obra é por sua vez significativa: tais critérios não são, em geral, aplicados aos escritores "realistas" dos primeiros dois terços do século na América Latina, que produziram uma literatura regionalista calcada sobre a literatura dos fins do século passado (o próprio Borges tem um número de contos que assim se classificam). Ao mesmo tempo, como lembra Larsen, a genealogia proposta para o "realismo mágico" que leva de Mário de Andrade, Asturias, Carpentier, Rulfo e Guimarães Rosa a García Márquez, Vargas Llosa, Fuentes e Cortázar tende a excluir obras não-modernistas da enumeração teleológica que se constitui nessa nova história literária da América Latina e que faz de Colombo, mais do que de Balzac, um antepassado literário dos escritores do "boom" (68). ${ }^{6}$ Em outras palavras tal genealogia tende a estabelecer uma separação — se não uma oposição- entre formas literárias que se ligam histórica e esteticamente.

O realismo propriamente dito está firmemente plantado na história literária e na cultura da América Latina; ele se manifesta em obras que diferem bastante entre si em termos de técnica e qualidade, mas pretende sempre representar lugares e culturas americanas particulares (pode-se citar, exemplificando, uma longa lista de autores das Américas tanto do Norte quando do Sul, de Frank Norris a John Steinbeck e William Faulkner, de Sarmiento a Euclides da Cunha, a José Lins do Rego, Graciliano Ramos, Caballero Calderón, Monteiro Lobato, ou Érico Veríssimo). É possível, com efeito, contradizer a genealogia (que começa com Colombo) proposta acima para o "boom" e afirmar que o realismo constitui uma base sólida sobre a qual se construiu tal modalidade expressiva, embora a relação se manifeste por vezes numa estratégia de oposição. A recuperação desse acervo realista por outras formas de expressão, como por exemplo o cinema, o teatro e certos programas de televisão, confirma a sua vitalidade e dá uma indicação além das que aparecerão adiante, do seu papel no desenvolvimento de obras em que ele se torna "mágico". Mas quando disseminadas fora das regiões de origem, tais obras realistas/regionalistas passam a caracterizar toda a literatura em que se inserem como documentária de problemas sociais e políticos, construindo, no caso em questão, da América Latina, um Terceiro Mundo que é só pobre, analfabeto, oprimido por um governo e por uma organização política ligados a sistemas injustos de produção e distribuição de bens e de serviços, tão superados quanto as obras que o representam. $O$ caso de Jorge Amado é típico dessa visão do romance

\footnotetext{
${ }^{6}$ Mais uma vez, deve-se lembrar a posição de Rodríguez Monegal, o qual mostra a continuidade entre as obras do realismo, do modernismo e do "boom"; no entanto essas últimas, mesmo quando firmemente plantadas numa "realidade" local fogem ao "telurismo ... suspeitosamente folclórico" das primeiras (77-8).

${ }^{7}$ Refiro-me aqui em especial ao caso brasileiro, que se voltou para obras "clássicas" de literatura como os romances e contos de Dinah Silveira de Queiroz, do Visconde de Taunay, de Jorge Amado, Graciliano Ramos, e Guimarães Rosa em busca de inspiração para filmes e telenovelas.
} 
latino americano, assim como o de García Márquez o é da que se lhe seguiu. O consenso crítico é de que a relação de Amado com o Partido Comunista dos anos trinta afetou a sua apresentação da situação brasileira, privilegiando o realismo regionalista para uso interno; ao mesmo tempo, esta relação dava-lhe acesso a uma vasta rede de distribuição para o mercado externo: os seus livros foram traduzidos em todos os países com sistemas marxistas de governo, e em outros por meio de organizações ditas progressistas de disseminação cultural. A produção e disseminação da obra de García Márquez foi contingente de forma semelhante, embora as condições em que se operou tenham sido diferentes.

Os anos sessenta viram a vitória um pouco surpreendente, na América Latina, da revolução de Fidel Castro, a qual trouxe às consciências de todas as estirpes políticas, a possibilidade de uma série de levantes semelhantes em países também governados por oligarquias corruptas e ditatoriais, apoiadas por interesses norte-americanos e europeus, os quais prepararam contra-ataques sob as formas de incentivos e punições. Mas esses mesmos anos foram também uma época de intensa criatividade intelectual, especialmente na América Latina, que resultou, do ponto de vista que interessa aqui, num aumento sensível da produção artística —ou seja, de artefatos culturais, tais como peças de teatro, filmes, poesia, música, romances. ${ }^{8}$ Ao mesmo tempo, conforme nota Ben-Villada, a produção artística dos centros de poder cultural estava estagnada: nos Estados Unidos, Updike escrevia Couples, sobre as aventuras sexuais de alguns casais numa cidadezinha da Nova Inglaterra; os países da Europa Oriental estavam encalhados no Realismo Socialista; a França produzia um cacetíssimo "nouveau roman"(BenVillada 8-10). Os artefatos culturais da América Latina então despertam no exterior um interesse condicionado em parte por esse sentido de fim de linha; o "boom" literário dentre cujos participantes alguns favoreciam o castrismo, mesmo quando não estivessem diretamente ligados a ele - faz parte desse conjunto de fenômenos políticos e culturais, e foi recebido como sinal da possibilidade de que uma visão diferente das condições políticas e sociais da América Latina seria não só possível, com também poderia fazer parte de uma renovação artística para além de suas fronteiras. A relação estabelecida entre os artefatos culturais do "boom" a "realidade" histórica faria parte dessa recolocação da América Latina; o aspecto "mágico" desse novo realismo tornaria possível reformular a discussão de suas condições políticas e culturais. ${ }^{9}$

\footnotetext{
${ }^{8}$ Seymour Menton talvez exagere ao estabelecer uma relação causal direta entre a atenção mundial dirigida à política e à literatura latino-americanas: afirma que Cem anos é um ótimo romance, mas que parte de seu sucesso se deve a Fidel Castro, cuja revolução aumentou a importância da América Latina (10).

${ }^{9}$ Dou-me conta de que essa leitura benévola do "boom" não é aceitável a certo número de críticos tanto de direita (que o acham perigoso porque torna a esquerda palatável a um vasto público leitor) quanto de esquerda (John Beverley diz que a literatura do "boom" é neo-liberal e mistificadora, e Tulio Halperín Donghi—citado por Larsen-explica que esses escritores se vêem na estranha posição de pertencerem "“à direita' em essência” e "“à esquerda' em aparência" [Larsen 71]).
} 
Não foi então pela primeira vez que houve uma defasagem entre movimentos culturais no Brasil e na América espanhola. Enquanto que na América espanhola, o "boom" trazia uma nova e forte consciência da possibilidade de afirmação e exportação de uma cultura autóctone, o Brasil sofria um sério abafamento cultural trazido pelo "endurecimento" progressivo da ditadura de 64 , a qual, no entanto, tinha sido precedida por uma grande euforia cultural, amplamente disseminada interna e externamente (numa explosão de produções teatrais, de literatura, do "cinema novo", da bossa nova). Dois fenômenos editoriais desses anos podem ser considerados semelhantes ao do "boom", embora as condições em que tiveram lugar tenham-lhes imposto uma estampa diferente. A diferença poderia apontar mais claramente certas características desses fenômenos cultural-literários. Mais ou menos dez anos antes da publicação de $\mathrm{Cem}$ anos, os livros mais vendidos no Brasil tinham sido Gabriela, cravo e canela de Jorge Amado (1958) e Quarto de Despejo de Carolina Maria de Jesus (1960). Ambos podem ser enquadrados nas categorias que mais atenção receberam dentre escritos "marginais" (no sentido de não terem tido origens euro-americanas) que, não obstante, tiveram sucesso de vendas e de crítica tanto no lugar de origem quanto no exterior: realismo mágico e "testemunho".

Gabriela é o primeiro romance da fase "branda" de Jorge Amado, ${ }^{10}$ depois de seu desligamento do Partido Comunista; precedeu-a imediatamente uma trilogia sobre a ditadura Vargas, trabalho marcadamente partidário. ${ }^{.1}$

Sem abandonar a defesa dos oprimidos, à qual tinha dedicado as forças plenas de sua imaginação e indignação nas obras anteriores, Amado adota um tom mais otimista, e propõe, nesse novo romance, a possibilidade de transformações positivas nas relações de poder entre homens e mulheres, cidade e campo, norte e sul do país; entre classes, e entre raças. O romance afirma um sentido de nacionalidade baseado na tolerância e no "jeitinho" que deixariam para trás os costumes mais intransigentes e violentos que talvez (e é essa uma leitura possível dos romances do "ciclo do cacau") tenham até sido

\footnotetext{
${ }^{10}$ Elizabeth Lowe faz um levantamento da recepção crítica a essa "nova fase" de Amado, e atribui parte do tom favorável à melhor integração do humor à obra; discute também várias das obras que se seguem a Gabriela e confirmam a transformação, especialmente Quincas Berro d'Agua, Tereza Batista e Dona Flor.

${ }^{11}$ A trilogia se intitula Os subterrâneos da liberdade, publicada em 1954. Larsen a considera a maior obra de Jorge Amado; Assis Duarte diz que "ela constitui o ponto extremo do engajamento amadiano, espécie de bizarro apogeu do modelo ficcional centrado na representação do oprimido pela via da perspectiva partidária" (209). Amado lembra que "a direção [do partido] pediu para ler os originais" e que, embora Prestes, chefe do partido, tenha se negado a exigir alterações, "outros dirigentes, ao contrário, queriam que alterasse..." (Assis Duarte, “Apêndice," 204). Quanto à data em que Amado deixou o partido, Larsen diz que foi em 1956, logo depois do famoso discurso de Khruschev contra Stalin e o "culto da personalidade"; praticamente acusa Amado de se ter deixado enganar pelo espetáculo absurdo das acusações de Khruschev; segundo Assis Duarte, Amado deixou o partido em 1955 (159).
} 
necessários nos tempos heróicos relatados em Terras do sem fim, ou em São Jorge dos Ilhéus, cujos personagens reaparecem em Gabriela.

Essas mudanças se manifestam em vários enredos entrelaçados: o livro começa com o assassinato de um casal adúltero pelo marido ultrajado, o qual, de rotina devia ter sido perdoado pela lei, e termina pela sua condenação. $O$ "árabe" Nacib e a retirante Gabriela, cor de canela, personagens centrais, começam por ter um caso amoroso, passam a uma relação conjugal que quer ser típica, a mulher submissa ao homem; esta se dissolve em adultério e anulação esperta, e se resolve numa associação sexual livre e inteiramente satisfatória aos participantes. O cozinheiro português é vencido pela brasileira Gabriela com a ajuda das divindades sincréticas do candomblé. O filho da poderosa família Falcão do Rio e de São Paulo financia uma linha de ônibus que liga o litoral ao interior e abre o porto aos grandes navios que levarão o cacau de Ilhéus diretamente aos mercados mundiais; ao contrário do que acontece em São Jorge dos Ilhéus, isso não resultará na exploração dos empresários nacionais pelas grandes companhias estrangeiras. O poderoso coronel que por muitos anos tinha governado a cidade e as plantações que a criaram e enriqueceram, cede frente à autoridade do voto e da imprensa, sem matar ninguém (embora tenha tentado, prisioneiro do passado); velhos inimigos reconciliam-se. Jerusa, filha dos poderosos Bastos, confraterniza-se com Gabriela, dançam nas ruas para festejar o Ano Novo, e a amizade entre raças e classes perdura para além desse período de "carnaval"(nos sentidos literal e Bakhtiniano). Em resumo, a injustiça, opressão e violência que tinham impelido os primeiros romances do cacau perdem as arestas e resolvem-se no que é, ao mesmo tempo, uma comédia utópica e uma reação aliviada a uma época de prosperidade; a vida mais fácil se espraia até aos humildes, confirmando os ideais de benevolência e tolerância para com prazeres sensuais - e para com diferenças políticas, sociais e raciais, que formam o pano de fundo ideológico de uma definição benigna da brasilidade.

Tudo isso não exclui a nota sombria: Gabriela é violentada pelo tio, o qual morre de fome, de sede e de fraqueza na fuga a mais uma das secas nordestinas, a caminho da promessa de água e trabalho em Ilhéus; e a nossa heroína é também seduzida pelo filho malandrote e inútil dos grandes Bastos, que não tem o costume de ver seus desejos frustrados exceto pela temível esposa. Malvina, filha de outro poderoso coronel, foge da mesquinhez do seu lar e de Ilhéus, decidida a não cair nunca na vida submissa da mãe, após uma tunda violenta do pai que a quer controlar. O retirante negro Fagundes quase paga com a vida sua obediência feudal ao patrão coronel que lhe ordena o assassinato de um inimigo político. Jerusa se mostra amiga de Gabriela para contrabalançar a sua rejeição, por classe social e raça, pelo resto da sociedade ilheense. O carnaval, os deuses afro-brasileiros, a boa política, os bons comes e o bom amor confrontam-se com inimigos reais e sérios. A presença desses desacordos e a sua resolução por meio da boa vontade e da intervenção de forças supernaturais permitem a classificação desse romance de Amado entre os que, do outro lado da divisória lingüística que corta o continente, usam de uma mistura do realismo clássico europeu 
e elementos temáticos e estilísticos autóctones que, transformando as convenções realistas, deram origem ao realismo chamado mágico.

De ambos os lados dessa divisória parece ter predominado a impressão de que o sentido da diferença nacional, constante nessas literaturas, apareceria mais claramente em rachaduras mais ou menos sutis dessas convenções do que por seu estilhaçamento. Aos leitores, tanto os de dentro quanto os de fora da cultura produtora, é assim possibilitado tomarem consciência da forma pela qual a própria realidade precisava ser redefinida a fim de que o discurso literário pudesse estabelecer um contato adequado com o seu fundo cultural. Gabriela proporciona uma visão positiva das diferenças entre a própria cultura e outra, internacional, a leitores "patrícios" (baianos ou brasileiros), os quais por serem leitores, se inserem nessa mesma cultura internacional, a qual se gere por suas próprias convenções e regras de representatividade. Leitores de outras partes têm a oportunidade de observar diferenças culturais que proporcionam ao mesmo tempo aventura e segurança. A continuidade entre a nova forma de Gabriela e os romances anteriores de Amado situados na mesma região, disfarça as inovações introduzidas —o novo romance pode ser lido também como uma simples continuação da saga que começa com Terras do sem fim, e continua com São Jorge dos Ilhéus. As referências à história, a acontecimentos contemporâneos, e ao processo de escrita que formam a estrutura de Gabriela e de Cem anos, enquadram essas obras numa seqüência de romances realistas que vão de Balzac a James Joyce, mas que também inclui o pioneiro do "realismo mágico" (ou do "real maravilhoso", sendo os termos provavelmente mais distintos do que diferentes), Alejo Carpentier. Em outras palavras, como estivemos indicando, esse romance de supra-realismo latino americano tem antecedentes duplos, europeus e autóctones - a forma específica pela qual esses antecedentes se combinam dá a cada uma dessas obras o seu sabor característico.

Para esclarecer melhor como se produz o efeito de Gabriela, é necessário sublinhar os seus elementos mágicos. Aparecem particularmente sob a forma dos elementos sincréticos da obra, cuja expressão mais marcante talvez seja o presépio das irmãs dos Reis. Este "representava, naturalmente, a natividade de Cristo," (55) mas a partir daí acrescenta, "democraticamente, ... patos, frangos, um leão, um tigre, e uma girafa" (55), e, entre figuras humanas, Santos Dumont, o Kaiser, o rei George V da Inglaterra, Lloyd George, Poincaré, Eleonora Duse, Zola, Dreyfuss, Castro Alves ("poeta da Abolição"), o bandido Antonio Silvino, Charlie Chaplin, Lenin, Lillian Gish, e Rodolfo Valentino (56).

Mais dramaticamente, no entanto, esse elemento contra-realista - se o virmos como uma forma de contestar o realismo como representação, não do mundo, mas de uma ideologia- aparece na integração cada vez mais freqüente de elementos afrobrasileiros na estrutura e enredo dos romances de Amado.

Desde quando pela primeira vez chegou a Salvador, Amado sentiu-se irresistivelmente atraído pelo candomblé, culto sincrético afro-brasileiro. Russell G. Hamilton traça não só essa atração, como também o reflexo, em sucessivos romances, do 
conhecimento cada vez maior, e do envolvimento cada vez mais detalhado e intenso do romancista com os rituais e praticantes do culto (245-46). ${ }^{12}$ As divindades africanas afetam o desenlace de pelo menos uma das linhas do enredo de Gabriela, precisamente a que reúne a heroína com seu amado Nacib e elimina o elemento estrangeiro (francoportuguês) que ameaçava a integridade nacional dos quitutes servidos no bar Vesúvio. Aparecem elas também no ponto alto de Dona Flore seus dois maridos. Desempenham um papel mais importante ainda em Os pastores da noite, onde Ogum "baixa" num padre durante um batismo, com efeito positivo para todos os personagens, ou na Tenda dos milagres, onde os orixás correm com a polícia. Como observa Maria Luísa Nunes, quando elementos de candomblé aparecem em romances anteriores a Gabriela, a posição narradora a seu respeito é um tanto crítica: a fidelidade de Jubiabá às divindades Yoruba é narrada de maneira positiva, mas a transformação estrutural necessária da sociedade brasileira, que remediará a sorte dos pobres e da população de cor do Brasil terá que vir como resultado "de ação política, e não da religião". Omolu, deusa da bexiga, é menos poderosa que a vacina (Nunes 92, 95). ${ }^{13}$ Quando Amado começou a se afastar dos postulados que por muitos anos e em muitos romances tinha aceito como caminho à solução dos problemas políticos e econômicos de seus personagens, não deixou de se preocupar com esses problemas. No entanto, quando passa a incluir em seus romances proporções crescentes do elemento não-europeu daquela que ele considera uma cultura especificamente brasileira, passa também a criar personagens e enredos que transgridem certas regras de causalidade física ou psicológica que, embora consideradas essenciais à definição tradicional do realismo, são levadas bem menos a sério pela imaginação popular; a própria morte, apoteose de alguns de seus heróis "progressistas", é desarmada e caloteada pelos heróis malandros da sua obra mais recente.

Enfim, a obra de Jorge Amado ocupa uma posição interessante numa configuração da oposição entre o realismo e o modernismo. Fica mais evidente essa posição quando se observa que a linha narrativa que vai de Terras do sem fim a São Jorge dos Ilhéus e a Gabriela constitui uma história contínua da região do cacau, mas ao mesmo tempo estabelece uma transição entre o modo realista direto e uma maneira moderadamente "mágica" que se intensifica em obras posteriores. É possível seguir essa transformação em relação a mudanças no "horizonte de expectativa" de um público doméstico e internacional. O Amado dos anos trinta vaza as experiências dos pobres e oprimidos no vocabulário do realismo da época, que se define em grande parte por sua oposição aos experimentos formais característicos do modernismo urbano brasileiro e internacional dos anos vinte - por exemplo, após uma discussão com Joaquim, herói proletário de São Jorge dos Ilhéus, o poeta Sérgio Moura concorda em rejeitar o idioma modernista do sul do Brasil e adotar o tom mais populista e ativo dos realistas

\footnotetext{
${ }^{12}$ Hamilton conta que assistiu a muitas cerimônias em que se encontrou com Amado "na sua capacidade administrativo-litúrgica de Obá" (Revista 3, 251).

${ }^{13}$ Para uma discussão mais completa, veja-se Maria Luísa Nunes.
} 
nordestinos. Mas mesmo em São Jorge, o elemento "mágico" aparece, não só na identificação de Joaquim com São Jorge e com a divindade africana Oxóssi, como também na figura de Rosa, amada por vários personagens e identificada com Iemanjá, deusa do mar. Mas o herói do romance, Joaquim desconfia dela: embora o elemento africano transforme a linguagem doutrinária de São Jorge, dando-lhe um tom local, ele não conta, antes de Gabriela, com aprovação autoral completa. Depois de Gabriela, sim, continuando em Dona Flor e seus dois maridos e em "A Morte e a morte de Quincas Berro d'Água" com proporções crescentes de "mágica", esbatendo-se cada vez mais a linha divisória entre os componentes europeu e africano da cultura brasileira. Por sua vez, esse esbatimento apaga outras distinções, inclusive a que separa vida e morte, essa mediada o mais das vezes por atividades sexuais que se dão sem sentimento de culpa e sem conseqüências, numa atmosfera festiva associada com um Brasil carnavalesco e anti-puritano. Gabriela constrói-se toda sobre uma congruência possível entre um realismo artístico que continua a focalizar a pobreza, e um lirismo que se estende à representação de toda uma sociedade mas que até então Amado tinha reservado principalmente aos pobres. No entanto, o lirismo também se transforma à medida em que a obra de Amado é aceita por um público e uma indústria editorial internacional: tempera-se com ironia, com a qual o romance introduz e idealiza as marcas de um descompasso cultural. Resumindo e parafraseando, seria possível exprimir da forma seguinte algumas das asserções do romance: é verdade que estamos numa sociedade na qual se espera que um marido enganado mate a mulher adúltera mas vamos contar a história do primeiro caso em que tal ação é punida pela lei; é verdade que estamos numa sociedade economicamente atrasada, baseada na exportação de matéria prima da qual só os intermediários tiram lucro - mas vamos contar de como se eliminou a da barra que fazia com que Ilhéus precisasse de intermediários; é verdade que estamos numa sociedade que oprime as mulheres, em que elas apanham por costume - mas vamos apresentar heroínas que escapam dessa situação; é verdade que estamos numa sociedade de política habitualmente corrupta - mas vamos conta a história de um político-tecnocrata que, enobrecido pelo sofrimento pessoal, põe a sua inteligência, energia e contatos honestamente a serviço da comunidade; é verdade que estamos numa sociedade em que, conforme vimos em livros precedentes, a violência e as à morte, o coronelismo e o banditismo, a exploração desapiedada do homem e da natureza formam parte da vida cotidiana - mas ao invés disso mostremos a aurora de uma era de cooperação e harmonia entre antigos inimigos. E contemos também a história da integração de uma população diversa e da intervenção de divindades africanas na vida diária do povo.

No caso de García Márquez, por outro lado, a crítica tende a se preocupar com a parte "realista" da caracterização, na medida em que pretenda assegurar a representatividade nacionalista da obra. Gene Ben-Villada nos informa de que García Márquez insistia em se classificar como um realista que simplesmente inclui mitos, crenças e explicações populares correntes de fenômenos reais como parte da realidade 
que representa (12). Especificamente Ben-Villada cataloga correspondências entre o que se relata em Cem anos e o que se conhece, por um lado, da história latino-americana e colombiana, e, por outro, da biografia do autor: o ataque de Francis Drake a Riohacha em 1596, as múltiplas guerras do século passado entre Liberais e Conservadores colombianos, as cartas trocadas entre o coronel Buendía e o general Rafael Uribe Uribe, sob cujo comando tinha lutado o avô do autor (102-103). E, tal como muitos outros, Ben-Villada nota também que o episódio da companhia de bananas "baseia-se firmemente em acontecimentos e detalhes específicos do período de 1900-1928," quando a United Fruit Company tornou-se "praticamente um país dentro do país" na região de Aracataca onde García Márquez se criara, e quando uma greve levou ao massacre de outubro de 1928. Segundo ele, até mesmo a chuva contínua que cai sobre Macondo após essas mortes tem a sua contrapartida real nas técnicas desenvolvidas pela França e pelos Estados Unidos no Vietnã para provocar aguaceiros estratégicos (104-105).

Pode-se dizer que o sucesso dos romances latino-americanos dos anos sessenta e setenta - tanto os do "boom", especialmente Cem anos, quanto Gabriela - pode ser atribuido, por um lado, ao conteúdo exótico, e por outro ao uso de certas técnicas narrativas, certas formas de manipular a linguagem, instaladas pelo modernismo e indicadoras de competência conforme as culturas "do centro". Sirvam como exemplos dessas técnicas modernistas a forma narrativa fragmentada, as descontinuidades cronológicas e de ponto-de-vista, a estrutura formal analiticamente recuperável, como a forma cíclica de Cem anos, uma certa auto-reflexividade que aparece nos manuscritos metaficcionais sobre a história de Macondo, assim como as paródias de linguagem literária, ou do "falar bonito" — desde a prosa pseudo-intelectual até aos versos melosos- que pontuam Gabriela. O exotismo aparece nos próprios incidentes relatados, que usam de material autóctone - histórico ou antropológico- legitimados também pelo modernismo "central" que se inspirava em artes africanas e latinoamericanas (para citar só três, vejam-se obras de Picasso, Darius Milhaud ou D. H. Lawrence), e assim preparados para o consumo tanto interno quanto externo.

Além disso, vários.críticos atribuíram a diferença entre Cem anos ou Gabriela e a literatura que os precede a uma questão de tom - àquela distância bem-humorada, que esbate as distinções entre o que seria considerado realista por um leitor familiarizado com os realismos latino-americano ou euro-americano, e o que seria aceito como real pelos personagens dos romances. A preferência por uma realidade de tapetes voadores a uma de telefones, de uma explicação "milagrosa" do gelo a outra "científica" (embora esta última torne possível o estabelecimento de uma indústria por um Buendía empreendedor), e a maneira tolerante e risonha pela qual a voz narrativa registra as esquisitices dos personagens, mesmo quando resultam em violência, constitui um contraste marcante com a intensidade de vozes narrativas anteriores. Essa recusa de apresentar os personagens como heróis, santos ou mártires ao mesmo tempo os aproxima de leitores que talvez também se considerem assediados por circunstâncias 
fora de seu conhecimento ou controle, e embota uma sensibilidade que convida ao combate à ignorância ou à opressão de pessoas representadas por esses personagens. Enquanto que os realismos anteriores confiavam na representação de tais dificuldades para servirem de convite à ação social, se possível por meio de tentativas de mudança das condições estruturais que lhes dão origem, essa nova forma de apresentação afirma a própria independência e maturidade ao preço da oportunidade de montar semelhante apelo. ${ }^{14}$ Consciente duma possível contradição entre seu método e o dos "realistas" García Márquez repreende o romance "comprometido" ("la novela comprometida") como sendo o mais "minoritário" possível, já que ninguém o lê (Fernández-Brazo 94).

Mas nem por isso os romances cujo realismo é "mágico" desdenham ou negam a injustiça ou miséria de que sofrem os seus personagens. A fuga à seca nordestina que leva Gabriela a Ilhéus faz parte do mesmo universo de violência, opressão e pobreza dos outros romances de Amado, tanto os que precedem quanto os que seguem Gabriela. O incidente da companhia de bananas retratado em Cem anos, assim como as referências à realidade problemática de guerras, da violência dos anos quarenta, e da vocação para a tirania dos governos de ambos os partidos políticos dominantes, reconhecível a partir de outras obras literárias e históricas, de etnologias e de tratados políticos, ancoram os romances num contexto que pouco tem de "mágico". ${ }^{15}$ Mas como essas referências são também percebidas como indícios da inserção dessas obras num contexto literário, numa série de obras que oferecem relatos autênticos e confiáveis de estados de coisas reais, o aspecto "mágico" impõe-se em certo momento como a uma das formas mais fiéis à "realidade" do realismo latino-americano. ${ }^{16}$

Surgem, no entanto, mais duas formas de resolver a questão da diferença entre o "real" e o "mágico" nesses romances: através dos conceitos críticos do mito, e, mais recentemente, do carnaval. A discussão mais completa dos aspectos mitográficos de Cem anos seria a de Michael Palencia-Roth, que entrelaça os mitos de origem e criação (Macondo como espaço anterior e posterior à queda), de incesto (conteúdo do estado da queda, que se identifica à história), e de apocalipse (a destruição e textualização de Macondo). Palencia-Roth contrasta esse fundo mítico do romance com as suas referências diretas à história, suas porções épicas, ou seja, os relatos de acontecimentos

\footnotetext{
${ }^{14}$ Sobre a postura convencionalmente política de seus textos, diz García Márquez: "Yo creo que tarde o temprano el mundo será socialista, quiero que lo sea, y mientras más pronto mejor. Pero también estoy convencido de que una de las cosas que pueden demorar el proceso es una mala literatura" (Vide Miguel Fernández-Braso 94).

${ }^{15}$ José David Saldivar menciona vários estudos sobre as referências históricas em Cemanos (29, notas 2,4), entre eles, os de Lucía Inés Menes, Mario Vargas Llosa e Regina Janes. Para Saldívar, Cem anos não é um texto marxista, embora tenha implicações radicais; por meio dele "exploramos tanto um texto pós modernista quanto um texto de cultura popular" (29).

${ }^{16}$ Stephen Hart fornece alguns exemplos; explica que o estilo de García Márquez mostrou-se "mais capacitado a expressar a realidade social do sub-continente do que quaisquer dos elementos do conteúdo [atenção à realidade, ou surrealismo] poderiam tê-lo feito isoladamente" (40). Veja-se também Katherine J. Hampares (121).
} 
políticos que correspondem aos fatos já citados da história da Colombia. Por outro lado, o conceito da carnavalização é usado por Arnold Penuel para explicar o esvaziamento de distinções entre contrários e a rejeição do "absoluto, de pureza, racionalismo, estereótipo e dogmas" (62); apóia-se em Bakhtin e em certas imagens rabelaisianas do romance (o pantagruélico José Arcadio com seu falo tremendo) para explicar a forma pela qual o romance questiona programaticamente todas as certezas culturais de seu meio. Ambos os críticos pretendem assim restabelecer o equilíbrio entre realismo e não-realismo (ou "mágica").

A esse tipo de esforço acrescenta-se a oposição do próprio autor a uma definição de seu trabalho por uma só palavra —ou mesmo duas. García Márquez parece preferir explicar o efeito de seu romance por uma questão de tom. ${ }^{17}$ Propõe assim, indiretamente, uma definição lata do realismo, que incluiria a perspectiva dos habitantes de lugares como Aracataca, e suas explicações dos fenômenos da vida quotidiana. Desta forma, García Márquez transfere o efeito mágico do romance para o leitor: a "estranheza" de seus romances tem menos a ver com a obra do que com as expectativas do leitor. $O$ "efeito do real" de Barthes é assim redefinido em termos explicitamente extra-textuais, culturalmente determinado, combinando-se com, e ao mesmo tempo questionando o "horizonte de expectativa" de Jauss.

Assim, enquanto que a parte realista do realismo mágico continua a seguir a estética oitocentista que tinha permitido ao romance latino-americano incorporar material regional às formas importadas da Europa (de Balzac, Zola, Galdós ou Eça de Queiroz), a parte "mágica" volta-se para os movimentos estéticos deste século, como o surrealismo e o pós expressionismo europeus. O processo é essencialmente o mesmo: estilisticamente afinado com as formas correntes, o romance latino-americano consegue apresentar o seu conteúdo autóctone como sendo ao mesmo tempo familiar e renovador. Só que desta vez atingiu o que não tinha atingido com a literatura de nacionalidade do século anterior: a inscrição desses romances num cânone internacional do qual até então a América Latina se tinha visto excluída.

Mas ao mesmo tempo em que, aberta para o questionamento modernista de todo o processo de representação, a literatura latino-americana consegue um lugar relativamente firme no mercado internacional, reabre-se a demanda de um realismo que no fundo não questione esse processo, que ocupe a posição de transparência do realismo tradicional, praticado anteriormente pela "cidade das letras" de Ángel Rama. Surge nesse momento uma escrita cuja autenticidade é garantida quanto ao conteúdo pela sua representação da pobreza e da opressão ainda características não só da imagem, como também de boa parte da realidade da América Latina, e quanto à forma, pela insegurança com que se serve dos instrumentos expressivos dessa mesma cidade das

\footnotetext{
${ }^{17}$ García Márquez conta a história de uma vizinha que veio mostrar à sua tia um ovo de forma estranha e ela, sem hesitar, como se fosse a coisa mais corriqueira, diagnosticou-o como sendo de basilisco, e determinou que devia ser queimado no quintal. Diria que a tia não é mágica, é cara-de-pau. Nem sempre os autores tem a última palavra...
} 
letras, a qual, naturalmente, controla as vias de comunicação. Ou seja, essa escrita não passa pela discussão entre Sérgio Moura e Joaquim, retomando um realismo premodernista. Mas essa viagem ao passado tem o seu preço: caracteristicamente, essa escrita chega ao público de forma mediata, apresentada por editores e outros intermediários, como que entre parênteses e com legenda explicativa.

Ou seja, no momento em que a obra de Amado começa a combinar um conteúdo mais ou menos irrealista com um estilo oral, usando formas literárias mais novas, aparece em cena uma escrita que aspira à literariedade, e representa o tipo de realidade do qual até então se tinha encarregado o romance realista/naturalista; afirma representar diretamente as camadas mais pobres e oprimidas da população e toma posição não só à margem da literariedade, mas à margem das próprias letras. Os diários de Carolina Maria de Jesus passam a ocupar o lugar do texto realista modelar. Esse texto, editado, como os testemunhos que apareceram mais tarde na América espanhola, mas escrito pela própria Carolina, traz em si a marca de uma literariedade mal-absorvida e ultrapassada, eivada dos lugares-comuns do "falar bonito" que Gabriela satiriza. Apesar de usarem de estratégias literárias encontradas em textos tradicionais, como a manipulação cronológica, o uso de imagens e figuras de linguagem, e outras, esses novos textos ameaçam colocar em xeque a crítica literária também tradicional. ${ }^{18} \mathrm{Como}$ são apresentados por seus editores como transcrições diretas da realidade nacional, solicitam uma crítica voltada a conteúdos mais do que à literariedade propriamente dita. No entanto, sua importância como textos depende também da possibilidade de enquadrá-los no sistema literário em que aparecem.

No fim dos anos 50, a recepção crítica oficial de romances estava em transformação na própria União Soviética - embora romances de Amado anteriores a Gabriela tivessem sido bem aceitos por seu conteúdo político e pela sua conformidade aos critérios estabelecidos pelo realismo soviético, foram também criticados por um resíduo de "naturalismo", pelo que se entendia principalmente seu erotismo; certas porções foram expurgadas antes da publicação em países do bloco soviético. Gabriela, no entanto, foi louvada apesar de se deliciar com os prazeres dos sentidos, tanto que "a expressão física do povo brasileiro" é vista simplesmente "como um reflexo de sua pureza espiritual [a qual], naturalmente, se opõe diametralmente ao mundo físico e espiritual do burguês" (Rougle 49).

Assim como no Brasil da década anterior, aparecem, em outras partes da América Latina, textos-testemunhos da pobreza crescente nas camadas sociais mais baixas e de várias formas de violência contra elas; em contraste com a prosperidade econômica de outros setores, e em conjunto com tomada de poder político por uma série de regimes ditatoriais, esses testemunhos aparecem, mais do que exóticos, perturbadores. São, no entanto, bem aceitos por um setor importante da crítica e por um público leitor para os quais a literariedade programática das obras do "boom" coloca em dúvida a sua representatividade. Ao mesmo tempo, num processo que essa crítica geralmente não

${ }^{18}$ Veja-se a "Introdução" de Marisa Lajolo aos poemas de Carolina Maria de Jesus. 
aborda, a competência (em termos das artes primeiro-mundistas) da literatura do "boom" ameaça a consciência de uma diferença entre produções culturais do Primeiro e do Terceiro Mundo, a qual só então começa a se mostrar indispensável. Larsen vê na recepção entusiasmada ao "testemunho" por parte do Primeiro Mundo um sintoma de uma conjuntura politico-literária que necessita fazer desses textos ao mesmo tempo uma marca do "'fim da literatura' e um limite cultural além do qual se acha uma 'diferença' pura, não-representável". Em confronto com a "autenticidade" dos "testemunhos", o modernismo se revela como "um quadro dominante de pressupostos", ou seja, ao mesmo tempo arbitrário e tirânico, ao estabelecer uma determinada definição de literariedade. Os "testemunhos" se constituem então em "um particular verdadeiro" (grifo de Larsen 18) que não tenha sido falseado pela "literatura". É só indiretamente, no entanto, que Larsen aponta para a relação entre o "testemunho" e o realismo dito "mágico".

Mas é precisamente pelas suas respectivas posições quanto a questões de representatividade e de literariedade nessas duas formas de escrita - tanto em termos de definição quanto de recepção - que se organizam a relações tanto do "testemunho" quanto do "realismo mágico" dentro dos sistemas literários em que se originam, e no mercado cultural internacional. Mas os testemunhos não foram sempre vistos (e nem o são unanimemente agora) como "diferença pura", como a voz inaudível do "subalterno" (tal como o define Gayatri Spivak), a qual ocupa uma posição importante na consideração de textos provenientes de ex-colônias européias. ${ }^{19}$

Debra Castillo, por outro lado, aceita a possibilidade de comunicação entre contextos de expressão e de leitura radicalmente diferentes (tais como os concebe Spivak) quando declara que "a base sobre a qual se assenta a narrativa testimonial para os leitores ocidentais é a sua absoluta fidedignidade; é indispensável que o narrador seja testemunha verdadeira" (294). Ou seja, para Castillo o "testemunho" se justifica, enquanto comunicação, pelas mesmas qualidades que tinham sido tradicionalmente atribuídas ao realismo. John Beverley também indica a existência de uma relação entre o gênero testemunho e a literatura do "boom" (embora com fins diferentes dos meus), ao afirmar que o livro de Rigoberta Menchú (obra-mestra do "testemunho" assim como Cem anos o é do "realismo mágico")é uma das obras literárias atuais mais interessantes da América Latina (133), e que o "testimonio representa o Real, ... que desmistifica as veleidades do neo-liberalismo [e] dos escritores da alta-cultura do 'boom' de falarem pela maioria dos latino-americanos" (138). Também ao diário de Carolina Maria de Jesus atribui-se essa qualidade desmistificante; segundo Robert M. Levine, a reação do público ao diário e à autora revelam claramente a existência de discriminação de classe e raça no Brasil, enquanto que o próprio texto, implícita e explicitamente, critica e

\footnotetext{
${ }^{19}$ Veja-se "Can the Subaltern Speak?" em que Spivak discute o "“verdadeiro' grupo subalterno, cuja identidade é a sua diferença". Em "A Literary Representation of the Subaltern", no entanto, Spivak examina o problema da literarização do subalterno por quem não o é.
} 
desmente o mito da democracia racial brasileira (82), de uma forma bem mais amarga que a dos textos de Amado. ${ }^{20}$

Ao mesmo tempo, no entanto, a consciência da presença de elementos de literariedade nesses textos cuja classificação e definição continuam a serem feitos em termos epistemológicos como o de "sinceridade" (expressão direta de um conhecimento também direto da realidade), ${ }^{21}$ estabelece uma simetria importante com o interesse pela representatividade dos romances do realismo "mágico". Por um lado, então, a literariedade marcante do realismo "mágico" leva a crítica a grifar o seu aspecto "realista", sua representatividade; por outro lado, a "representatividade" do testemunho leva a crítica, num segundo momento, a questionar a precisão ou a generalidade das informações que fornece. Levine cita estudos que mostram diferenças claras entre a organização social e econômica de favelas no Rio de Janeiro e em São Paulo, sendo essas últimas menos coesas, seus habitantes menos solidários (56). ${ }^{22}$ Tornam-se assim os diários de Carolina o registro da vivência de um indivíduo em determinado ambiente, mais do que de toda uma classe. E a conferência de David Stoll, em Berkeley, em $1989,{ }^{23}$ desmentindo certos fatos autobiográficos dramáticos relatados por Rigoberta Menchú ocasiona uma reconsideração da literariedade de sua obra, tanto no sentido da configuração do texto, quanto no do controle exercido pela "autora" e pela "editora" em prol do efeito desejado sobre o público leitor. No que depois do alarde inicial começa a se parecer com uma retirada estratégica, Hendley conclui que Menchú deve ser lida não "'literalmente" mas "“literariamente"“(68). E Doris Sommer deplora que "certos leitores acadêmicos tenha fixado a sua atenção numa só parte da aula de linguagem [dos testemunhos], na parte que insiste sobre a realidade referencial" (Sommer 122). ${ }^{24}$ Tais análises também começam a examinar o papel dos editores dessa escrita que inicialmente sempre se apresenta como "transparente" à realidade. Os editores determinam a ordem da narrativa, "corrigem" a gramática, cortam ou acrescentam comentários ou episódios. A análise de suas atividades chama a atenção à construção dos textos e a outros problemas do âmbito tradicional da crítica literária, mesmo questões bem antigas, como por exemplo a relação entre a palavra oral e a

\footnotetext{
${ }^{20}$ Levine nota que Carolina foi criticada por se vestir bem e pasear pela elegante Rua Barão de Itapetininga (62), e por não se comportar de acordo com a etiqueta da classe média (81).

${ }^{21}$ Veja-se John Beverley, "The Margin at the Center ..." (94). Neste ensaio, Beverley opõe a "sinceridade" à "literariedade".

${ }^{22}$ Levine refere-se, entre outras, à obra de Janice E. Perlman.

${ }^{23}$ Veja-se George B. Handley, "“It's an Unbelievable Story' ..." (67).

${ }^{24}$ Segundo Sommer, por meio de um método autobiográfico "metonímico", característico da autobiografia feminina e do "testemunho", essas obras não procuram tomar o lugar do leitor, nem representá-lo como é o caso na biografia masculina, "metafórica"; ao invés, convidam o leitor/a a acompanhar a autora, viver lado a lado com ela. A ênfase crítica passa da relação do texto com a realidade extra-textual para a sua relação com o público.
} 
escrita, debatida desde o Romantismo. ${ }^{25}$ No fim, tomando em conta as complementaridades entre os textos considerados "mágicos" e os vistos como "realistas", aparece um sistema textual que conta com um número e variedade de obras suficiente para que se possam distribuir por elas em diversas proporções os elementos significativos de literariedade e literalidade em torno dos quais se dá boa parte do debate crítico sobre o realismo, seja contestado, engajado ou alienado, ou sobre o "testemunho", o naturalismo, o modernismo, e o "realismo mágico".

Segundo explica Antonio Candido em "Literatura e subdesenvolvimento", a mudança de um idioma literário o qual, por processos afins mas distintos, supervalorizava o exotismo e exibia um certo acanhamento do estilo, possibilitou à literatura latinoamericana romper as barreiras da dependência econômica e cultural. Essa mudança tem lugar ao mesmo tempo em que se instala uma visão mais precisa da relação entre a cultura da América Latina e outras, dominantes (Candido 140-162). Um internacionalismo mais pronunciado da parte das culturas de maior poder, somado a um conhecimento mais detalhado da dinâmica da pobreza e da falta de poder talvez tenha ajudado literaturas que os enfocassem a ganhar relevância internacional, não como um elemento pitoresco de cor local, mas como um fenômeno por sua vez internacional, cujas manifestações locais teriam implicações mais amplas. Alargaria-se assim a possibilidade de se encontrar um público leitor para obras produzidas entre uma população composta em grande parte de analfabetos, de semi-analfabetos, ou de pessoas sem o hábito da leitura, que, ao mesmo tempo, constitui o protagonista principal dessas produções as quais assim contribuem para a acumulação de algo como uma massa crítica de literaturas nacionais. Nessa literatura autóctone, por sua vez, encontram-se modelos literários que diminuem ou modificam o impacto dos estrangeiros, o que pode ter resultado na liberdade formal característica desses novos escritores internacionais do hemisfério sul: García Márquez lê Kafka, Joyce, e Faulkner, mas também E. Caballero Calderón, a Doña Bárbara de Rómulo Gallegos, ou os Recuerdos del Porvenir de Elena Garro; ${ }^{26}$ Vargas Llosa lê Euclides da Cunha; todos lêem Juan Rulfo, Jorge Luis Borges e Alejo Carpentier.

Paradoxalmente talvez, essa presença de um público internacional pode funcionar como um incentivo a uma "literariedade" mais pronunciada, e marcar a independência do realismo em relação a romances regionalistas (nacionais) tradicionais. O elemento "poético" da obra de Amado, e o "mágico" da de García Márquez tornam-se então necessários à representação de condições locais, sem terem de se ligar a alguma fórmula predeterminada que marque seu material como nacional ou assegure sua legibilidade internacional. Nesse sentido, e seguindo ainda o argumento de que essas formas

\footnotetext{
${ }^{25}$ Lembre-se a fórmula de William Wordsworth, que queria empregar a linguagem real de pessoas (diz ele homens) reais-mas também, e mais a propósito, o gesto (modernista) iconoclasta de Rachel de Queiroz, que teve a ousadia de começar uma frase escrita com um pronome oblíquo, reproduzindo a fala do povo.

${ }^{26}$ Isso, pelo menos, segundo Rodríguez Monegal (79).
} 
literárias (realismo, modernismo, realismo mágico, testemunho) ocupam lugares cada vez menos isolados e portanto cada vez menos distintos num sistema literário, não seria paradoxal que uma das formas inovadoras de um texto literário de alta complexidade seja a incorporação de elementos de expressão popular ou de massa — nesse sentido já foram objeto de atenção crítica a afinidade de certos textos de Amado com a assim chamada literatura de cordel; o ritmo oral da narração de García Márquez; a presença, em ambos, de um tesouro de sabedoria popular, e a sua reconstrução de uma imagem do mundo condicionada por crenças arcaicas coexistentes com as do século atual. ${ }^{27}$

Mas, naturalmente, a história ainda não acabou. Conforme nota Marisa Lajolo, a publicação da poesia de Carolina Maria de Jesus sugere mais uma questão importante. Eivados de incorreções políticas e gramaticais, de lugares-comuns do romantismo e do parnasianismo cuja canonicidade continua firmemente inscrita nas camadas populares semi-alfabetizadas, semi-inclusas na cidade letrada, formam os seus poemas "uma poesia e uma militância" que soam "em falso" mas para as quais "hão que se criar os olhos de ler". A questão é de como e onde encaixar essa "poesia forte, cheia de sotaques e extremamente oportuna por textualizar [...] uma cultura que quase nunca chega ao livro impresso, mas que, quando chega, como chegou esta de Carolina, assinala, em sua violência infratora, a exclusão dos pactos e protocolos da cultura, dos cidadãos e cidadãs também excluídos do mundo econômico" (Lajolo 59). Textos assim indigestos confundem as categorias com que se aprendeu a manipular os realismos com ou sem adjetivos, a reconhecer e medir literariedades. Espinhosos, literaria e ideologicamente, desafiam uma sistematização completa e assim talvez garantam uma certa irredutibilidade que ao mesmo tempo marca um sistema semiótico aberto e uma identidade cultural resistente à comodificação pelo mercado internacional - reverso perigoso da medalha da fama internacional.

O risco, no entanto, é necessário.

Mas à medida que a literatura da América Latina se torna mais complexa e completa, capaz de incorporar a realidade cultural e econômica específica aos seus lugares de origem, talvez seja oportuno desviar a discussão de considerações de representação e de representatividade para examinar de forma menos simplista a interrelação entre estratégias literárias e o sistema completo de uma literatura latinoamericana quer nacional quer regional. Ou seja, talvez seja oportuno estudar as literaturas da América Latina da mesmo forma como se estudam as da Europa ou dos Estados Unidos, vistas ao mesmo tempo e de forma não- problemática, como "nacionais" - inglesa, alemã, francesa, italiana, russa, etc.- e européias, ou, ao mesmo tempo regionais ou "étnicas" — sulina, da Nova-Inglaterra, chicana, afro-americanae americana. Desta forma será possível ver, dentro de um mesmo esquema geral não

\footnotetext{
${ }^{27} \mathrm{O}$ tratamento ficcional mais completo dessa coexistência de épocas históricas, vista como característica da América Latina e usada como elemento estruturante do romance, aparece em Os passos perdidos de Alejo Carpentier. Constitui também um elemento importante de $L a$ Guerra del fin del mundo de Mario Vargas Llosa.
} 
só as várias formas, igualmente legítimas, com que se assinalam e definem as relações sempre indiretas entre a literatura e seus contextos, como também as várias formas pelas quais a vivência desses contextos é textualizada conforme as funções assinaladas a uma variedade de expressões. Uma das maneiras pelas quais as literaturas das regiões "subdesenvolvidas" do mundo se caracterizam, do ponto de vista de um público mais amplo, internacional, é pela sua constante preocupação em explicar os pobres aos ricos, os fracos aos poderosos, os oprimidos aos opressores. Essa expectativa não só nivela diferenças internas como limita as possibilidades pelas quais várias camadas da população podem interagir. Mas a "literariedade" das obras de García Márquez e de Amado as torna acessíveis ao público e aos mercados internacionais sem as isolar de um público nacional vasto. A presença nessas literaturas de maneiras diferentes de encarar uma realidade considerada digna de expressão literária, assim como a presença de textos que tomam a liberdade de absolutamente não se preocuparem com a temática do subdesenvolvimento pode bem ser um sinal, não da alienação de certos autores e seu público, mas da presença de uma definição de nacionalidade segura, de um sistema literário completo, de um processo avançado de desenvolvimento cultural, que permita tanto a autores quanto à crítica e ao público dedicar uma só parcela de seus esforços e de suas emoções a questões de representação e representatividade.

\section{OBRAS CITADAS}

Ahmad, Aijaz. "Jameson's Rhetoric of Otherness and the 'National Allegory'". Social Text 17 (1987): 3-25.

Amado, Jorge. Gabriela, cravo e canela. Rio de Janeiro: Martins, 1958. (Em inglês, Gabriela, Clove, and Cinnamon. Trad. de James L. Taylor and William Grossman. New York: Avon, 1962).

Ben-Villada, Gene. Garcia Márquez: the Man and his Work. Chapel Hill: The Unversity of North Carolina Press, 1990.

Beverley, John. "The Margin at the Center: On Testimonio (Testimonial Narrative)". Decolonizing the Subject: The Politics of Gender in Women's Autobiography. Sidonie Smith and Julia Watson, eds. Minneapolis: University of Minnesota Press, 1992. 91-114.

"The Real Thing (Our Rigoberta)". Modern Language Quarterly 57/2 (1996): 129-139.

Bernstein, Charles. "Poetics of the Americas". Modernism/Modernity 3/3 (1996): 123.

Candido, Antonio. "Literatura e subdesenvolvimento". A educação pela noite e outros ensaios. São Paulo: Ática, 1987.

Castillo, Debra. "Reading Loose Women Reading". Modern Language Quarterly $57 /$ 2 (1996): 289-303.

Fernández-Braso, Miguel. La soledade de Gabriel García Márquez (Una conversación infinita). Barcelona: Editorial Planeta, 1972. 
Flores, Angel. "Magical Realism in Spanish American Fiction". Hispania 32/2 (1955): 187-192.

García Márquez, Gabriel. Cien años de soledad. Buenos Aires: Sudamerica, 1967. Hamilton, Russell G. "Afro-Brazilian Cults in the Novels of Jorge Amado". Hispania 50/2 (1967): 242-252.

Hampares, Katherine J. "Gabriel García Márquez: A Synthesis of Inter-American Reality”. Inti: revista de literatura hispánica 16-17 (1983): 111-23.

Handley, George B.. "'It's an Unbelievable Story': Testimony and Truth in the Work of Rosario Ferré and Rigoberta Menchú". Violence, Silence, and Anger: Women's Writing as a Transgression. Charlotteville and London: University Press of Virginia, 1995. 62-79.

Hart, Stephen. "Magical Realism in García Márquez's Cien años de soledad". Inti: Revista de Literature Hispánica 16-17 (1983): 37-52.

Jameson, Fredric. "Third World Literature in the Era of Multinational Capitalism". Social Text 15 (1986): 65-88.

Janes, Regina. Gabriel García Márquez: Revolutions in Wonderland. Columbia: University of Missouri Press, 1981.

Jauss, Hans Robert. "Literaturgeschichte als Provokation der Literaturwissenschaft". Literaturgeschichte as Provokation. Frankfurt am Main: Suhrkamp, 1970. 144270.

Jesus, Carolina Maria de. Antologia pessoal. José Carlos Sebe Bom Meihy, ed. Rio de Janeiro: Editora da Universidade Federal do Rio de Janeiro, 1996.

Quarto de Despejo. São Paulo: Editora Ática, 1995 [Francisco Alves, 1960]. (Child of the Dark, the Diary of Carolina Maria de Jesus. Trad. de David St. Clair. Nova York: Mentor Books, 1962).

Lajolo, Marisa. "Poesia no quarto de despejo, ou um ramo de rosas para Carolina". Carolina Maria de Jesus, Antologia pessoal. Rio de Janeiro: Editora da Universidade Federal do Rio de Janeiro, 1996. 37-61.

Larsen, Neil. Reading North by South: On Latin American Literature, Culture, and Politics. Minneapolis: University of Minnesota Press, 1995.

Levine, Robert M. "The Cautionary Tale of Carolina Maria de Jesus". Latin American Research Review 29/1 (1994): 55-83.

Lowe, Elizabeth Schlomann. “The 'Nova' Jorge Amado". Luso-Brazilian Review 6/ 2 (1969): 73-81

Menes, Lucía Inés. “Cien años de soledad: Novela de 'La Violência"'. Hispanoamérica 13 (1976): -23.

Menton, Seymour. "Ethnocentric Criticism". Latin American Literary Review 11/22 (1983): 7-13.

Magic Realism Rediscovered, 1918-1981. Philadelphia: The Art Alliance Press, 1983.

Mills, Maylan C. "Magic Realism and García Márquez's Eréndira”. Literature and Film Quarterly 17/2 (1989): 113-122. 
Nunes, Maria Luisa. "The Preservation of African Culture in Brazilian Literature: The Novels of Jorge Amado". Luso-Brasilian Review 10/1 (1973): 86-101.

Palencia-Roth, Michael. Gabriel García Márquez: la línea, el círculo, y las metamorfosis del mito. Madrid: Editorial Gredos, 1983.

Penuel, Arnold. Intertextuality in Garcia Márquez. York, South Carolina: Spanish Literature Publications Co., 1994.

Perlman, Janice E. The Myth of Marginality: Urban Poverty and Politics in Rio de Janeiro. Berkeley and Los Angeles: University of California Press, 1976.

Rama, Angel. A cidade das letras (La ciudad letrada). Introdução de Mario Vargas Llosa. Prólogo de Hugo Achugar. Trad. de Emir Sader. São Paulo: Brasiliense, 1985.

Rodríguez Monegal, Emir. El boom de la novela latinoamericana: Ensayo. Caracas: Editorial Tiempo Nuevo, 1972.

Rougle, William. "Soviet Critical Responses to Jorge Amado". Luso-Brazilian Review 21/2 (1984): 36-56.

Saldívar, José David. "Ideology and Deconstruction in Macondo". Latin American Literary Review 13/25 (1985): 29-43.

Sommer, Doris. “'Not just a Personal Story': Women's Testimonios and the Plural Self". Life/Lines: Theorizing Women's Autobiography. Bella Brodszki and Celeste Schenck, eds.. Ithaca: Cornell University Press, 1988. 107-130.

Süssekind, Flora. OBrasil não élonge daqui. São Paulo: Companhia das Letras, 1990. Spivak, Gayatri Chakravorti. "A Literary Representation of the Subaltern". In Other Worlds: Essays in Cultural Politics. New York and London: Routledge, 1988. 241-68.

“Can the Subaltern Speak?". The Post-Colonial Studies Reader de Bill Ashcroft et al.(eds.). London: Routledge, 1995. 24-28.

Vargas Llosa, Mario. García Márquez: historia de un deicidio. Barcelona: Barral, 1971.

Wasserman, Renata R. Mautner. Exotic Nations: Literature and National Consciousness in the United States and Brazil, 1830-1930. Ithaca: Cornell University Press, 1994. 